\title{
De la Clase de Historia a la Televisión: La Política Educativa Argentina en Torno a la Cuestión Malvinas a 30 Años de la Guerra
}

\author{
Verónica Tobeña ${ }^{1}$ \\ ${ }^{1}$ Pesquisadora do Consejo Nacional de Investigaciones Científicas y Técnicas (CONICET) da Faculdade \\ Latino-Americana de Ciências Sociais (FLACSO). Buenos Aires, Argentina. \\ E-mail: verotobena@gmail.com, https://orcid.org/0000-0002-1538-6482
}

\section{INTRODUCCIÓN}

$\mathrm{E}$ n un texto ya clásico dentro de la literatura dedicada a la temática de la enseñanza de la historia aparece desde su título una inquietud que queremos tomar prestada para este trabajo a modo de hipótesis. Se trata de la obra de Marc Ferro Cómo se cuenta la historia a los niños en el mundo entero, que reconstruye y analiza con rigor los distintos discursos historiográficos y versiones existentes sobre tiempos pretéritos que participan del conocimiento del pasado (nacional, étnico, religioso o europeo, según corresponda al objeto de análisis que recorta en cada capítulo). Allí se postula:

La imagen que tenemos de otros pueblos, y hasta de nosotros mismos, está asociada a la Historia tal como se nos contó cuando éramos niños. Ella deja su huella en nosotros para toda la existencia. Sobre esta imagen, que para cada quien es un descubrimiento del mundo y del pasado de las sociedades, se incorporan de inmediato opiniones, ideas fugitivas o duraderas, como un amor... al tiempo que permanecen, indelebles, las huellas de nuestras primeras curiosidades y de nuestras primeras emociones (Ferro, 2007:19).

Con motivo de la conmemoración de los 30 años de la guerra de Malvinas se produjeron por la iniciativa y el apoyo del Estado Nacional numerosos productos audiovisuales destinados a abordar este capítulo de la historia argentina ${ }^{1}$. El presente artículo se propone analizar uno de esos materiales coproducidos y transmitidos por el canal de televisión Encuentro, perteneciente al Ministerio de

DADOS, Rio de Janeiro, vol.62(2):e20170033, 2019.

http://dx.doi.org/10.1590/001152582019177 
Educación de la Nación. Se trata de "La asombrosa excursión de Zamba en las islas Malvinas", un programa educativo en torno a la historia argentina que se dirige a un público infantil comprendido entre los 6 y los 12 años en el lenguaje de los dibujos animados. Dicho programa surge de una apuesta fuerte del Ministerio de Educación Nacional por transformarse en un vector ineludible de la historia con la que los niños se forman a la que hace referencia la cita de Ferro (2007); forma parte, asimismo, de un paquete más amplio y variado de contenidos generados en un esfuerzo de la política educativa por "dejar su huella" en la imagen que niños y niñas tienen de la Argentina, su país, a través de los relatos históricos.

Esa formación es medular para los Estados modernos pues no solo brinda a las generaciones nuevas el banco de información necesario para incorporarse al diálogo social, sino que también y, fundamentalmente, modela en esos niños y niñas su ser nacional: un conjunto de atributos y disposiciones ligados a su condición geográfica, política, jurídica, cultural y social y, no menos importante, a su identificación moral con la argentinidad. En suma, se trata de un proceso formativo ineludible para que la idea de patria cobre espesor.

El papel que juega el Estado en la enseñanza de la historia ha tenido tradicionalmente un propósito que es transmitir una determinada versión de los hechos históricos, que no es cualquier interpretación del pasado sino una síntesis consensuada para oficiar como la versión legítima. La historia que cuenta el Estado tiene como horizonte construir la identidad nacional, contarnos quiénes somos y a dónde vamos. La pregunta por el ser argentino, por sus raíces, sus rasgos y su futuro en la que estos relatos oficiales sobre el pasado deben introducir a las nuevas generaciones se inspira en la imaginación histórica para dar contextura y densidad temporal al país que hoy somos, para dar legitimidad al camino recorrido y otorgarle valor a las opciones con las que hoy contamos. En este sentido, la historia es importante no solo porque nos provee un pasado común y nos cuenta cómo llegamos al presente, sino ta mbién porque justifica el camino a transitar hacia el futuro (Jelin, 2001; Carretero y Voss, 2004; Carretero, Rosa y González, 2006). Pero es importante tener en cuenta que "toda visión global de la historia constituye una genealogía del presente. Selecciona y ordena los hechos del pasado de forma que conduzcan en su secuencia hasta 
dar cuenta de la configuración del presente, casi siempre con el fin, consciente o no, de justificarla" (Fontana, 1982:9).

En el contexto argentino la forma en que la historia nacional se transmite en la escuela constituye una línea de investigación asentada que cuenta con estudios que abordan incluso los albores de nuestro sistema educativo. En El fracaso del proyecto argentino. Educación e ideología, Carlos Escudé (1990) hace un interesante análisis del origen del autoritarismo y el nacionalismo extremo en la Argentina centrado en la educación patriótica, lo que a sus ojos constituye un mecanismo de adoctrinamiento en la escuela primaria. Su hipótesis es que

"la cultura política fue distorsionada de una manera contraria al progreso $\mathrm{y}$ al buen funcionamiento de las instituciones (liberales) por medio de un adoctrinamiento autoritario y dogmático, grandilocuentemente chauvinista" (Escudé, 1900:XVIII).

Para intentar describir cómo se materializó ese adoctrinamiento a partir de 1908, el autor utilizó como fuentes publicaciones educativas de distintas épocas, fundamentalmente El monitor de la educación y diversos manuales escolares. Escudé ya había desarrollado en un libro anterior su hipótesis, cuya intención fue llevar a cabo un relevamiento de textos de enseñanza para verificar la medida en que elementos del nacionalismo territorial argentino habían sido difundidos por el sistema educativo (1987). En ambos libros se subraya el componente territorial que caracteriza al nacionalismo argentino y se señala la vigencia de la cuestión Malvinas como un núcleo persistente de este rasgo ${ }^{2}$.

También el estudio sobre la revista Billiken (1994) de la analista cultural Mirta Varela se inscribe en la línea de trabajos que problematizan cómo se encara la enseñanza de la historia nacional en el ámbito educativo. En su caso, el foco está puesto en una revista de la industria cultural, pero con fuerte presencia en la escuela, ya que logra penetrar sus muros de la mano de las maestras y de los niños que la consumen y que fueron moldeando su sensibilidad histórica al calor de las páginas de dicha publicación. Esta investigación, por su parte, pone de relieve la apuesta de este magazine por formar al ser nacional y cultivar un sentimiento patriótico a partir de una construcción de los protagonistas de nuestra historia donde abundan el bronce y los estereotipos. 


\section{MARCO TEÓRICO Y ESTRATEGIA METODOLÓGICA}

El aparato conceptual en el que abreva este estudio está vinculado a herramientas teóricas orientadas a dimensionar la doble función que tiene la enseñanza de la historia en la escuela: por un lado, una función cognitiva que tiene que ver con transmitir aquellos conocimientos historiográficos y del pasado de la nación que socializa a las nuevas generaciones en una disciplina relevante para su instrucción formal así como para su formación política y el ejercicio de su ciudadanía; $\mathrm{y}$, por otro lado, una función afectiva vinculada al cultivo de la identidad nacional, el arraigo del sentimiento de pertenencia a un territorio y a una cultura común (Morin, 2000). Estas dos lógicas, la disciplinar y la emotiva, tensionan la enseñanza escolar de la historia en tanto una apunta a cumplir objetivos cognitivos mientras que la otra tiene propósitos societales y afectivos (Carretero, 1006; Carretero y Kriger, 2010). Estas referencias teóricas tienen la virtud de poner de relieve la convivencia de dos criterios reñidos en el seno de una educación que se asume como científica, ya que al criterio de verdad que rige a la historiografía se superpone el criterio emotivo que motoriza el arraigo de la identidad por medio de la enseñanza de la historia. Verdad e identidad constituyen órdenes de legitimación que pertenecen a sistemas de valores que no son homologables, de modo que esta doble fuente rectora para el ejercicio de la historiografía y la enseñanza de la historia no está exenta de potenciales conflictos.

En este sentido, seguiremos aquellas vertientes teóricas que asuman el campo de la enseñanza de la historia como un espacio delicado, atravesado por múltiples criterios de construcción y diversas expectativas, haciendo foco en el problema moral y ético que se cuela en la construcción de un discurso como el historiográfico, que a priori solo parece comprometer una dimensión científica pero que en rigor está atravesado también por elementos de otro tenor (Carretero y Montanero, 2008; Ruiz Silva y Carretero, 2010). En este punto nos será de utilidad la consideración de este problema en los términos de Ruiz Silva y Carretero (2010), quienes advierten sobre las exigencias de generar procesos de identificación con la nación en términos de "construcción de narrativas éticas del pasado" (Ruiz Silva y Carretero, 2010), ya que el mandato de identificación alienta la supresión de detalles incómodos reñidos con la moral y/o la ética. 
En cuanto a la estrategia metodológica, este estudio retoma el análisis del discurso (Verón, 1985) a partir del cual es posible trazar un mapa con las principales características del programa de dibujos animados, identificando su nivel temático, retórico y enunciativo. A su vez, hace foco sobre las estrategias narrativas utilizadas para presentar los contenidos históricos. El estudio apunta a indagar cómo se presenta la historia al público infantil, cómo se organizan y se seleccionan los hechos que se cuentan, de qué modo se procesa un episodio traumático como la guerra para un destinatario en edad escolar, qué valoraciones se transmiten, qué representaciones del ser nacional y del ser británico se construyen y qué recursos estilísticos y estéticos se ponen en juego para todo ello.

El marco teórico que aporta la semiótica será una referencia ineludible para identificar los diversos recursos en relación a la construcción de representaciones (de la guerra, del ser argentino, del ser británico, etc.). Valiéndonos de estos instrumentos intentaremos caracterizar los principales personajes y figuras conceptuales que el programa representa.

\section{¿POR QUÉ ZAMBA?}

En general el Estado cuenta la historia a través de la escuela. Esta constituye "su brazo cultural", la institución privilegiada para canalizar las referencias culturales y el ideario simbólico que, con su labor pedagógica, sostiene el papel que juega el Estado en el proyecto político moderno. No parece accidental la incursión casi compulsiva que el Ministerio de Educación argentino viene haciendo en la producción de material audiovisual desde el 2007; dicha proliferación de oferta cultural oficial en formato audiovisual más bien parece formar parte del modo en que los actores estatales buscaron esquivar la tan mentada crisis de la escuela apostando precisamente a ese espacio de circulación cultural que en el imaginario más extendido funciona como némesis de la escuela: los medios masivos de comunicación. En este sentido, cabe subrayar el esfuerzo realizado por el Estado nacional de intervenir en la escena cultural apelando a soportes y lenguajes menos explorados por las iniciativas culturales oficiales, esfuerzos que parecen hablarnos de una preocupación por reducir la brecha actualmente existente entre la escuela y la cultura contemporánea ${ }^{3}$.

Quienes conozcan "La asombrosa excursión de José Zamba", más allá de la simpatía o el rechazo que sus distintos capítulos pueda 
despertar en función de posicionamientos político-ideológicos sobre los eventos del pasado allí representados, seguramente concuerden en reconocer la calidad estética del producto, aprecien el dinamismo que sostienen todos sus capítulos y la capacidad de mantener la atención del espectador. Probablemente este consenso radica en que se trata de una propuesta que, a pesar de surgir desde un espacio televisivo estatal, se concibe dentro de los parámetros estéticos de los productos de la industria cultural de masas y de las gramáticas de producción de la televisión más comercial ${ }^{4}$. Es posible pensar que el hecho de que este programa se constituya en todo un fenómeno en términos de audiencia se deba a una concepción de la propuesta en sintonía con la oferta de carácter más comercial. Pero además del éxito de público Zamba cosecha fans y, como suele ocurrir cuando el público se entusiasma o se identifica con algún personaje de la industria cultural, este goza de un plus de posibilidades que los empresarios de los medios suelen exprimir al máximo -como ocurre con el mundo de consumo que acompaña los productos exitosos de Disney, entre los que se incluye todo tipo de merchandising y el parque de diversiones homónimo. Zamba, que encarna una suerte de niño argentino promedio en cuanto a las representaciones más extendidas de las disposiciones que presentan hacia la escuela los chicos (Zamba se aburre en la escuela) y que visibiliza un fenotipo escasa o nulamente representado por la oferta televisiva masiva (Zamba es de tez y cabello oscuro y es oriundo de Clorinda, Formosa), se presta a las lógicas de consumo y a las experiencias multimediales típicas de los personajes del mainstream. Existen remeras de Zamba, musicales de Zamba, un parque temático y una ampliación de las áreas del conocimiento que progresivamente se suman a la propuesta original del canal Encuentro que abrevan en Zamba como personaje y en su mundo para situar otras nuevas, lo que permite pensar que este niño formoseño ya está funcionando como una suerte de membresía o sello de calidad.

Como señalamos anteriormente, no vamos a concentrarnos aquí en lo que ocurre con "Zamba" en su encuentro con su público. Sin embargo, es significativo para los objetivos que se propone este artículo tener en cuenta que ese éxito de público está expresando que niños y niñas comprendidos entre los 6 y los 12 años de edad han accedido, precozmente en el caso de los más chicos ya que no tienen una asignatura en la escuela primaria que englobe contenidos de historia nacional ${ }^{5}$, a un espacio social de intercambio y a un mundo de sentidos del que difícilmente participarían si no fuera por su 
exposición a este dibujo animado. Estos niños y niñas conocen sobre San Martín, Belgrano, Juana Azurduy, Sarmiento, Rosas; saben que antes de conquistar su independencia la Argentina estaba bajo dominio español, conocen buena parte de las peripecias que su país tuvo que pasar antes de ser lo que es hoy y, como argentinos, se saben deudores de ese pasado y ligados a esa historia. "Zamba" tiene la virtud de despertar la curiosidad de los chicos en un área del conocimiento que suele ser difícil de abordar en la escuela. También ha demostrado constituir un rico campo de identificaciones posibles para su público: niñas que se disfrazan y juegan a ser Juana Azurduy, niños que son fans de San Martín o que para el día de Reyes Magos piden de regalo muñecos de granaderos, son algunas de las anécdotas que pude recabar conversando con padres de chicos que gustan de "Zamba".

\section{¿POR QUÉ LA GUERRA DE MALVINAS?}

El hecho que aborda el capítulo que aquí vamos a analizar, la guerra de Malvinas, constituye un evento de nuestra historia que a nuestros ojos reúne un conjunto de condiciones que lo tornan rico para nuestro análisis. Es rico para nosotros, sobre todas las cosas, porque encierra una tensión entre el pasado y el presente propia de los discursos que buscan fijar sentidos sobre hechos que aún nos tocan por su cercanía temporal y personal, y también por ser de índole sumamente traumática. El de Malvinas fue el único conflicto bélico en el que se vio envuelto el país a lo largo del siglo XX y, según algunos historiadores especializados en el tema, el duelo y la reflexión social sobre esta guerra ha tendido a solaparse con el duelo y la reflexión social sobre la última dictadura militar que la impulsó (Lorenz, 2013; Guber, 2012). Esta subsunción del conflicto bélico es lo que ha impedido, según estos especialistas, una elaboración social informada sobre la causa Malvinas y mantiene pendiente la deuda de la sociedad en torno a esta cuestión.

Otro filón que encontramos en el tema Malvinas que lo torna interesante para convertirlo en objeto de nuestro análisis es que este ha vuelto a cobrar espesor dentro de la trama política actual. De este modo, el hecho de que una propuesta oficial sobre un evento como la guerra de Malvinas en el momento en que la cuestión Malvinas se reinstala en la agenda política en el marco de una gestión que hace de la revisión del pasado reciente un pilar fundamental de su propuesta de gobierno y de su liderazgo, se vuelve atractivo para observar 
cómo pasado, presente y futuro pueden verse en una síntesis como la propuesta por "Zamba".

Otra dimensión que permite auscultar de forma privilegiada el análisis de un hecho como el de la guerra de Malvinas es el de la cuestión de lo nacional, de la nación como problema, es decir, cómo se plantea la cuestión nacional en el programa de dibujos animados, cómo se construye esa relación entre un territorio y una nacionalidad para los chicos desde esta propuesta, pero también cómo se asocian rasgos, valores, tradiciones, actitudes, según la pertenencia nacional.

\section{MALVINAS: "ES UNA INJUSTICIA QUE HAY QUE REPARAR, PERO CON LA GUERRA SIEMPRE SALE MAL"}

"La asombrosa excursión de Zamba en las islas Malvinas" cuenta, como señalamos anteriormente, con el beneplácito del público, de modo que ha logrado hacerse dueño de una gramática discursiva atractiva para los más chicos. Veamos cómo y con qué contenidos logra la difícil tarea de interpelar a su público.

Hay dos conceptos centrales, dos ideas rectoras que organizan la presentación de la cuestión Malvinas como tema: la idea de que las Malvinas son argentinas, que es injusto que ese territorio argentino esté en manos de Inglaterra, por un lado; y, por otro, que la guerra no es el camino para reivindicar ni subsanar esta injusticia. Estas ideas se nombran, se verbalizan a lo largo de todo el programa en forma de canciones y en los diálogos que el protagonista, Zamba, tiene con quienes lo abren al conocimiento de este capítulo de nuestra historia, repitiéndose de forma sostenida a lo largo de todo el texto. El capítulo inicia con una presentación sumamente concentrada de la información que da cuenta del derrotero sufrido por las islas Malvinas desde el siglo XVI. Los datos y los hechos que se presentan ilustran las disputas sobre la soberanía de ese territorio que se dieron a lo largo de la historia. Esta información está introducida y coronada (a modo de estribillo, de fórmula musical, de latiguillo), por la siguiente expresión: "Es una injusticia que hay que reparar pero con la guerra siempre sale mal". Este segmento de presentación de contenido se resuelve apelando a la lógica de videoclip: es un fragmento muy dinámico en el que se incluye mucha información que es difícil no asociar a la carga de datos que la escuela está acostumbrada a hacer memorizar a los alumnos, pero en este caso tiene el mérito de ser 
presentada de forma lúdica, a modo de canción, haciendo ese cúmulo de datos algo ameno y dinámico. Dicha información se transmite en un relato que resulta claramente inteligible, coherente, dejando así rápidamente planteados los elementos que funcionan como datos ineludibles para entender la conflictividad que atraviesa las Malvinas y que forman parte de los antecedentes del desenlace bélico ${ }^{6}$.

$\mathrm{Al}$ cabo de los veinte minutos que dura este capítulo, la pregnancia de estas dos ideas (que es una injusticia que Inglaterra niegue la soberanía argentina sobre las Malvinas ${ }^{7}$ y que la guerra no es el modo de resolver este conflicto) parece asegurada. La música que incluye este texto es pegadiza y él se repite por lo menos dos veces. En varias ocasiones, además, se reitera en los parlamentos de los personajes, incluida la última sección de este capítulo que, como todos los de esta serie, culmina con una síntesis final de parte de Zamba donde da cuenta de todo lo aprendido en cada excursión al pasado. Una pregunta pedagógica que realiza un personaje significativo del capítulo habilita esta suerte de lección que rinde Zamba. Dicha lección funciona de algún modo como un intento de sistematizar y organizar los puntos más sobresalientes del tema abordado por cada capítulo.

Ahora bien, decíamos más arriba que estas dos grandes ideas a la luz de las cuales dicho programa educativo encara la enseñanza de la guerra de Malvinas son ideas que se nombran, que se verbalizan, con las que se insiste desde la palabra. Es decir, son ideas que no se dejan libradas a la elaboración de la audiencia, sino que se hacen explícitas y de este modo se las convierte en axiomas: Las Malvinas son argentinas (o, la invasión a un país está mal, es una injusticia que hay que reparar) y la guerra no es el medio para remediar una injusticia ("con la guerra siempre sale mal").

Al mismo tiempo, en otro nivel discursivo, el texto despliega otros sentidos sobre la guerra, sobre lo que significa empeñar la vida por una causa justa como la de Malvinas. Según nuestra percepción, esos otros sentidos sobre la guerra que despliega el texto no se valen de la palabra en lo que esta permite soportar en tanto lógica logocéntrica sino que la palabra es un instrumento más dentro de una lógica poiética de construcción de sentidos. Con esto queremos decir que en torno a la guerra "Zamba" despliega un nivel de construcción de sentidos que abreva en recursos dramáticos que incluyen la palabra, pero que no están dominados por su lógica secuencial, 
lineal, racional, sino que esta se encuentra al servicio de una lógica emotiva, afectiva, ya que es indisociable de la imagen, de la música, de los planos, del ritmo, de la atmósfera, y de aquellos instrumentos que están al servicio de despertar un pathos. En buena medida, todo el texto está concebido desde esta lógica y por eso cobra forma de programa de dibujos animados y no de texto escolar. Sin embargo, hay tramos del relato en los que la matriz dramática del texto resulta omnipresente como el de la escena que se da como preámbulo de la batalla final (la batalla de Monte Longdon) en la que el soldado Sapucai, tras exponer a Zamba las dificultades que ponen en situación de desventaja al ejército argentino ${ }^{8}$, les habla a sus compañeros de batalla en medio de la noche, con una voz quebrada ante lo que se presenta como una situación límite para el personaje, ambientado por una melodía de suspenso que musicaliza el drama de la escena, las imágenes de los soldados que se asoman de las trincheras con caras que exhiben las marcas de la guerra (rostros lastimados, con frío), con bombas cayendo a su alrededor y un cielo que se ilumina de forma intermitente por los bombardeos ingleses. La alocución de Sapucai apela a ideas como el valor, el heroísmo, la lealtad, el honor y el orgullo nacional.

Amigos, ha sido un honor pelear junto a ustedes frente a un enemigo tan poderoso. Es hora del esfuerzo final, vamos a dejarles claro a los ingleses que las Malvinas son nuestras y que siempre va a ser así. Y si alguno de nosotros no logra sobrevivir, que esa sea una forma de quedarse en nuestras islas para siempre y resistir hasta que nos las devuelvan. Valor, mis amigos. Defendamos lo que es nuestro.

El dramatismo de la escena es el más álgido de todo el capítulo. Tras esta escena que da lugar a la batalla final, se simboliza la muerte de algunos de esos soldados a los que Sapucai hablaba ${ }^{9}$ y Zamba, junto con el público, descubre que perdimos la guerra. Todos aquellos elementos negativos que se asocian al conflicto bélico, desde el axioma que lo descarta de plano "porque con la guerra siempre sale mal" hasta aquellos elementos que se van destilando a lo largo del texto para mostrar el sinsentido de la guerra (el frío, la falta de preparación, de infraestructura, de municiones, de experiencia, la disparidad de las tropas, la guerra como inmolación a la que obliga un dictador y como ocurrencia o capricho de un tirano), son dotados de ciertos matices y condimentados con sentidos heroicos a partir de esta escena que cobra visos épicos. Es como si todo ese 
sinsentido que recubre a la guerra contribuyera a la idea heroica de la guerra, como si todos esos sinsentidos en vez de llevar a impugnarla condujeran a redimir la injusticia vivida por sus víctimas a través de una reivindicación heroica de la guerra que la propone como una gesta patriótica. En esa alocución, el soldado Sapucai ofrece un discurso laudatorio de la entrega de la vida a la nación, justifica la inmolación a la que manda ese dictador a sus soldados como una "forma de quedarse en nuestras islas para siempre y resistir hasta que nos las devuelvan", llama a defender "lo que es nuestro", con la vida, aunque por ese medio "siempre salga mal".

Fue Edgar Morin (2000) quien planteó que la enseñanza de la historia es insustituible para el arraigo de la identidad nacional; el cariz patriótico que adopta la prédica del soldado en el marco de un contexto dramático, como es el preludio a la batalla que termina por reafirmar la derrota argentina, constituye una evidencia de la afirmación de Morin. También validan su perspectiva la inclusión de la Marcha a las islas Malvinas que se inserta inmediatamente después de que se muestra la batalla final, en un fragmento del capítulo que funciona como un cierre emotivo de la excursión realizada por Zamba a este territorio. La puesta en pantalla de dicha marcha permite ligar a la audiencia con una pieza emblemática del repertorio de la simbología nacional en una versión especialmente concebida para este marco. La marcha se acompaña con imágenes que ilustran a la audiencia en la topografía, el clima y la fauna de las islas. Pero el acompañamiento de la pieza musical desde las imágenes también permite hilvanar algunos de los sentidos inscriptos en la letra de la marcha con significantes que constituyen íconos de nuestra identidad nacional, permitiendo anclar así el significado de la argentinidad. Así es que se ofrece a las nuevas generaciones una foto que ya forma parte de nuestra colección iconográfica como argentinos, como es la imagen de la cartografía de las islas Malvinas, en este caso enmarcadas por un arco iris que tiene los colores de la bandera argentina, un sol amarillo en el centro y la leyenda "Malvinas Argentinas" debajo. Mientras suena el pasaje del himno que reza "Las Malvinas argentinas en dominio ya inmortal", los colores que priman en la pantalla son los de la bandera argentina: fondo celeste, cruzado en el centro nuevamente por el arco iris albiceleste y con San Martín y Belgrano en el centro, quienes rápidamente se abren para dar lugar a los soldados que lucharon en Malvinas, en lo que parece una parábola del ingreso de los combatientes de Malvinas al panteón de los héroes nacionales, al ponerlos en serie con los próceres de la patria ${ }^{10}$. 
"La asombrosa excursión de Zamba en las islas Malvinas" no constituye así una excepción dentro de los productos concebidos para la enseñanza de la historia desde inquietudes que tienen que ver más con la construcción de la identidad que con una función cognitiva. "Zamba" no logra superar la convencional tensión entre las dos lógicas que articulan la enseñanza escolar de la historia, deudoras de los dos grandes idearios filosóficos que se fusionaron en el nacimiento del Estado nación: el ilustrado universalista y el romántico particularista. El primero de estos idearios aporta la lógica disciplinar ya que de él se desprenden los objetivos cognitivos de la historia escolar dirigidos a la formación de conocimientos historiográficos; el segundo contribuye a una lógica emotiva puesto que tiene propósitos societales orientados a la formación del sentimiento nacional (Carretero, 2006; Carretero y Kriger, 2010). Los objetivos románticos de la enseñanza de la historia están orientados a fomentar sentimientos de lealtad a la nación (incluso por encima del valor de la vida), a brindar sustrato para la construcción de la identidad nacional, a proveer relatos y tradiciones en los cuales entroncar el mito de la identidad nacional y a despertar la solidaridad entre los connacionales. La formación de las capacidades críticas y el desarrollo del pensamiento histórico constituyen, por su parte, los objetivos ilustrados que hacen a la enseñanza de historia.

La lógica romántica desde la que enseña la historia "Zamba" se constata, no solo en el rol de eslabón que asume en la reproducción y la socialización de símbolos patrios y de emblemas nacionales (la insistencia en la bandera y sus colores, en la idea del panteón nacional, en la Marcha a las Malvinas, en la cartografía de las islas), sino también en la construcción ligeramente maniquea que hace del nosotros nacional y de la otredad británica, construcción que la ambigüedad y la ausencia de algunos datos que hacen al contexto político y civil de la guerra a nivel nacional contribuyen a delinear.

Entre esos datos que el texto no repone hay dos que a nuestro juicio son significativos y que merecen cobrar contornos claros para aquellos niños y niñas que el programa televisivo busca incorporar al diálogo social: se trata, por un lado, de los kelpers, los isleños que habitan las Malvinas, y, por otro, del nombre de Leopoldo Galtieri, del dictador, de ese tirano que ocupaba entonces el poder a la fuerza y empujó al país a la guerra ${ }^{11}$. 
Respecto a los primeros, cabe señalar que en Zamba brillan por su ausencia, no hay referencias a la existencia de este sujeto en el programa y por lo tanto tampoco está problematizada cuál es la construcción soberana que los isleños defienden. La ausencia de los kelpers es grave porque saca de la ecuación la evidencia sobre la que se apoya el argumento de la autodeterminación de los pueblos, base empírica principal a partir de la cual se alzan los rechazos a los reclamos de soberanía argentinos. De este modo, las nuevas generaciones están privadas de un dato sustantivo para la discusión sobre la soberanía de las islas Malvinas como la existencia de habitantes históricos de esas tierras y su negativa a integrarse a una identidad argentina. A la luz de esta ausencia parece difícil que puedan hacerse un juicio crítico e informado para discernir sobre el argumento de la autodeterminación de los pueblos como vía a partir de la cual encarar el conflicto.

Respecto a Galtieri, ¿por quéel texto decideno nombrarlo? ¿Qué política histórica sostiene la decisión de negarle nombre propio a esta figura? ¿Qué teoría pedagógica fundamenta la circulación innominada de una imagen para señalar a un sujeto histórico? ¿Cómo emancipar desde la enseñanza de la historia a las nuevas generaciones si empezamos por ocultarle información vergonzante? ¿Cómo hacer de la enseñanza de la historia una herramienta útil para la construcción de alternativas de futuro si ante una evaluación histórica negativa sobre el pasado decidimos obviar ciertos datos? Si de lo que se trata es de agotar con la transmisión del pasado la trascendencia histórica de Galtieri, es decir, si lo que buscamos es dar vuelta definitivamente la página de ese capítulo oscuro de nuestra historia y poner al dictador en la galería de los traidores a la patria, ¿no deberíamos leer sin saltearnos una palabra dicho capítulo para que podamos reconocer en el futuro cualquier denominador común que pueda presentar el devenir histórico con la etapa más nefasta de la historia argentina? ¿De qué modo conseguimos dar menos trascendencia histórica a la figura de Galtieri: vaciándolo o saturándolo de sentidos? ¿No es la reposición de la mayor cantidad de información posible lo que permite dejarlo definitivamente atrás -empezando por asignarle un nombre propio- antes que la decisión de recubrirlo de un manto de dudas que no hacen más que despertar desconcierto sobre esta figura?

Si la figura de Galtieri adopta contornos difusos en el texto, este desdibujamiento se articula con el papel ambivalente que se concede 
allí a la sociedad civil, que prácticamente está invisibilizada. El extendido apoyo que recibió de la sociedad civil la guerra está representado de forma críptica en el texto ya que, al igual que ocurre con el dictador, este apoyo tampoco se nombra; se muestra, y se lo hace vagamente, en una imagen que dura muy pocos segundos y que ocupa un lugar marginal de la pantalla, por lo que resulta difícil captar su significado a aquellos que carecen de competencias históricas sobre el período. Ese apoyo se pone en imágenes en una escena muy creativa del programa en la que se muestra a Galtieri operando una palanca que domina una suerte de dispositivo encargado de convertir a civiles en soldados (entre los que se encuentra Sapucai, el maestro de Zamba) y que se produce de cara a una manifestación popular que agita sus banderas argentinas y salta bajo una lluvia de papelitos albicelestes, en lo que simboliza un apoyo entusiasta a la guerra.

Esa presencia difusa del apoyo de la sociedad civil a la guerra sumada a la opacidad que rodea la figura de Galtieri, privado de nombre propio por la textualidad del programa, favorece la formación de una idea de un nosotros exento de fallas, desprovisto de atributos reprochables. "Cuando regresamos entendimos que el teniente general que nos había mandado a la guerra había armado todo para distraer al pueblo, ya que era un tirano y un dictador que estaba destruyendo el país de a poco. La guerra nunca es un buen camino Zamba", le explica Sapucai a Zamba en el presente cuando este le pregunta qué pasó después de la guerra. La aventura de la guerra en la que se había embarcado el pueblo argentino tiene en el engaño del tirano su explicación; el pueblo y los combatientes fueron víctimas de su capricho. Esta exculpación del pueblo de su error en virtud del engaño bajo el que apoyó la guerra entronca con la presentación del dictador como un dato anecdótico, aislado, huérfano de tradición alguna en la historia argentina, para dar como resultado una idea del nosotros candorosa, virtuosa.

Es que cuando la enseñanza de la historia tiene por objetivo central contribuir al arraigo de la identidad nacional

(...) tiende a valorar positivamente al propio grupo social, explicar sus características en términos esencialistas, no históricos, rechazar las fuentes que ponen en conflicto una versión complaciente de la propia historia, (...) recuperar en forma acrítica el rol de ciertos personajes históricos emblemáticos (en muchas ocasiones a través de la dicotomía 
‘héroes y villanos') y tender lazos de permanencia y continuidad entre los hechos y personajes del pasado y la actualidad del grupo nacional, entre otros aspectos (Carretero y Montanero, 2008:139).

Si la enseñanza de la historia se asume como medio a partir del cual generar procesos de "identificación con la nación de uno", es inevitable que se instale el problema de "la construcción de las narrativas éticas del pasado" (Ruiz Silva y Carretero, 2010) para quien debe administrar los símbolos y los relatos sobre los que se sostiene un ethos colectivo de carácter nacional. Es por eso que la enseñanza de la historia es algo delicado, un campo de interacción social atravesado por múltiples criterios de construcción y diversas expectativas. En tanto disciplina científica se debe antes que nada al criterio de verdad ${ }^{12}$; sin embargo, el papel que debe cumplir para el arraigo de la nacionalidad la abre a una contradicción, ya que debe conciliar los aspectos cognitivos que impone el criterio disciplinar con los aspectos emotivos y afectivos que implica la formación de la identidad nacional, los cuales abrevan en discursos del orden de la ética y la moral. Esta convivencia no puede darse entonces sin tensiones y plantea una contradicción de difícil conciliación, porque no solo están en juego las interpretaciones del pasado (esto es, la manera en que significamos eso que ocurrió en el pasado), sino también cómo nos posicionamos moralmente en relación con ese pasado (esto es, qué implicancias morales tiene sobre nosotros ese pasado a partir de cómo procesamos su herencia) (Ruiz Silva y Carretero, 2010: 46). ¿No hay una contradicción en el modo en que se posiciona frente a la guerra el texto que aquí analizamos? ¿El axioma que se repite como un mantra a lo largo del dibujo animado ("con la guerra siempre sale mal") logra menoscabar los sentimientos de lealtad a la nación, de orgullo por la patria y de identificación con un territorio que el dibujo cultiva? ${ }^{13}$ Esos sentimientos son el humus para que la fibra nacionalista se geste ${ }^{14} \mathrm{y}$ pueda ser activada eventualmente en nombre de alguna causa justa (como lo fue Malvinas).

En este sentido, merece un párrafo aparte el tratamiento de la otredad británica que realiza "Zamba", puesto que en alguna medida buena parte del componente moral de la identidad nacional suele estar dado por la manera en que esa construcción se opone a la alteridad. Desde ya, en el caso que aborda el texto que aquí se analiza, una guerra, el conflicto entre ambos países no pasa fundamentalmente por una cuestión simbólica, sino que se basa en un enfrentamiento bélico real, 
de modo que no caben en la caracterización del otro como enemigo que hace el texto elucubraciones que especulen sobre la exaltación del nacionalismo, tal como la movilización del concepto de enemigo puede suponer. Pero sí cabe preguntarse por los rasgos que asume ese enemigo en el texto porque ello nos aporta sustrato para comprender la dimensión moral que compone la identidad nacional que allí se construye.

En primer lugar, entonces, cabe señalar un rasgo físico que se ubica en los británicos y se opone a la fisonomía que los personajes argentinos adoptan en el texto: los ingleses son rubios, de tez blanca y ojos claros, mientras que los colores de pelo, tez y ojos del argentino son oscuros. No es que esta construcción estereotipada del aspecto de unos y otros resulte espuria por ser contrafáctica (efectivamente, el fenotipo anglosajón y el latino muestran cierta afinidad con esos estereotipos), pero sí hay que señalar el peligro que conlleva la operación de estereotipar como mecanismo simplificador y exagerador de ciertos detalles, que coadyuvan a una percepción monolítica de la identidad y la alteridad ${ }^{15}$.

El estereotipo es a su vez el recurso que el texto utiliza para caracterizar al inglés como enemigo al asociarle a este sujeto nacional distintas señas particulares que terminan por contornear el perfil del villano, que también se nutre por oposición de los rasgos antagónicos con que se asocia a los personajes argentinos. El carácter villano del inglés se va delineando a lo largo de todo el texto, en algunos casos apelando a figuraciones más trilladas y obvias y en otros más sutiles. Lo mismo ocurre como contrapartida con el carácter heroico que se atribuye al ser argentino. Inicialmente, se presenta al inglés como "gente prepotente", reforzado desde el discurso visual por una representación que se apoya en la figura del pirata ${ }^{16}$, a la que se le imprime una actitud matona a partir de la dinámica que se da a sus movimientos. Este imaginario del pirata que se activa para dar cuenta del papel representado por este sujeto nacional a lo largo del siglo XIX se actualiza cuando se trata de transfigurar el signo negativo que se le atribuye a este actor histórico en el siglo XIX al contexto del siglo XX, esto es, la situación de guerra y, al mismo tiempo, los parámetros estéticos que hacen a cómo construye la idea del villano la industria cultural contemporánea. Así, en el contexto de la guerra, convergen en la figura del inglés algunos símbolos de poderío y ciertos clichés sedimentados por el género de aventuras dentro del formato de 
animación infantil que configuran al sujeto como villano o malo. Esos símbolos de poderío están dados por todos los elementos que va destilando el texto al servicio de la representación de la superioridad material del ejército inglés (su ventaja numérica, su mayor experiencia, su mejor equipamiento), que además de mostrarse se verbalizan. Dicha superioridad se evidencia, por ejemplo, en la primera escena de la excursión de Zamba al pasado, cuando este acompaña al piloto Chispa en su misión de derribar un portaviones inglés, y un único avión argentino con tecnología elemental ${ }^{17}$ debe lidiar con dos aviones enemigos con tecnología de punta ${ }^{18}$ que lo persiguen y que además están comandados por pilotos con equipamiento mucho más sofisticado que el que muestra el piloto argentino ${ }^{19}$. Otro ejemplo de la desigualdad existente entre los ejércitos está representado en el diálogo mantenido por Sapucai y Zamba en una trinchera justo antes de que se desate la batalla de Longdon, donde el primero instruye al segundo sobre las dificultades que atraviesa nuestro ejército ${ }^{20} \mathrm{y}$ también en las escenas que componen dicha batalla, la batalla final que da la victoria a los ingleses. Allí las provisiones del ejército enemigo simbolizadas al estilo de un videojuego en el zócalo de la pantalla se renuevan constantemente en un reservorio que parece no tener límites, mientras que para el armamento argentino las municiones llegan a su fin en el medio de una contienda que resulta dramática porque por primera vez se ponen en pantalla las bajas humanas ${ }^{21}$. El contraste material y numérico que se escenifica en dicha batalla en favor del ejército inglés es inversamente proporcional al valor y al heroísmo que se atribuye a Sapucai, quien a pesar de las frágiles condiciones en las que se enfrenta al enemigo (con un ejército menos numeroso, escasas municiones y en lo que se perfila como una derrota segura) ordena a sus hombres retroceder y se ofrece como escudo para cubrir el frente de guerra. El texto construye así el valor de Sapucai al exponer cómo este soldado le pone el cuerpo a la batalla, no solo por las agallas y la fraternidad que muestra hacia los otros combatientes ofreciéndose a cubrirlos, sino en virtud de la lucha de igual a igual que mantiene con un soldado gurka ${ }^{22}$ al que logra reducir sin más recursos que su fuerza física y su valentía.

Entre los clichés en los que abreva el texto que contribuyen a una percepción del inglés como el villano de esta historia, se destacan el uso de una risa de sonido macabro ${ }^{23}$ que está puesta siempre al servicio de mostrar el goce que le despierta a los personajes que representan a este sujeto nacional ${ }^{24}$ la desventura argentina. También 
suman en este mismo sentido los insultos que dedica a sus enemigos cuando fracasa en una misión el soldado inglés (que siempre es el mismo improperio: “imalditos!”) o detalles como el de la calavera que decora el avión inglés que se muestra en la primera escena de la guerra. La operación al servicio de la cual están la risa, los insultos y la calavera es la de colocar del lado del inglés actitudes y símbolos que funcionen como índices de su malignidad. Pero sobre todas las cosas, el rol del villano que juegan en esta historia los ingleses está sustentado, fundamentalmente, por el cinismo que anima su defensa de la soberanía británica sobre las Malvinas, que además resulta más cruel en tanto se despliega en presencia del niño inglés y coadyuva a su confusión, como puede apreciarse en el diálogo que se da en la siguiente escena:

Niño inglés (llorando): Él dice que las islas Falklands son argentinas.

Soldado inglés: Bueno, puede ser que originalmente hayan sido argentinas, pero eso fue hace mucho, no hay que temer. Lo importante es que ahora nosotros estamos aquí y no se las vamos a devolver (risa macabra del soldado). Zamba: Eso es injusto, son nuestras, ustedes nos las robaron.

Soldado inglés: En estas islas no hay lugar para todos, pequeño. ¡Regresa a tu país ahora! (apuntándolo con el fusil y provocando el llanto del niño inglés).

Mientras la guerra es codificada desde el lado argentino como una gesta patriótica, en tanto país imperialista no se asigna a Inglaterra una significación patriótica del conflicto bélico sino una muestra de la fuerza imperial que ejerce sobre otras naciones ("Por qué nos persiguen", le pregunta Zamba al piloto Chispa al comienzo de su excursión al pasado. "Los ingleses no quieren devolvernos las islas, hay países que creen que son los dueños del mundo", le explica el piloto argentino).

Es difícil argumentar en contra de la enseñanza que intenta transmitir Chispa a Zamba con este comentario, que busca socializar de un modo eficaz a los jóvenes en el papel histórico que ha desarrollado el Reino Unido a lo largo de varios siglos. Sin embargo, cabe señalar que este resulta un pie inmejorable para introducir aquí una reflexión que, además de reponer el patrón imperial que ha caracterizado históricamente la geopolítica británica ${ }^{25}$, interpele aspectos que hacen a la discusión sobre la cuestión Malvinas que ayuden a "aprender a pensar históricamente" (Carretero y Montanero, 2008:135) ${ }^{26}$. Este ejercicio contribuiría a aportar instrumentos cognitivos que sirvan a 
la puesta en cuestión y a la evaluación crítica de las propias versiones y evidencias históricas sobre las que toda reconstrucción del pasado se forja, al tiempo que contribuiría, como contrapartida, a una apertura hacia las evidencias sobre las que se sostienen las historias otras, estableciendo un horizonte argumentativo más amplio y más rico para la imaginación histórica ${ }^{27}$.

\section{PALABRAS FINALES}

¿Cómo enseñar sobre la guerra a los más chicos? ¿De qué modo se transmite reconocimiento y gratitud hacia quienes dieron la vida por causas justas, mostrando, a su vez, lo equivocado del método, la insensatez de la guerra? ¿Cómo honrar a los caídos y a los veteranos de Malvinas al tiempo que se condena la guerra? ¿Cómo se deconstruye para el público infantil la experiencia de la guerra y el contexto que la hizo posible? ¿Cómo se mantiene la reivindicación de la soberanía sobre las Malvinas sin abandonar la condena hacia la guerra? ¿Cómo evitar sustancializar o esencializar la nación en la enseñanza histórica de la guerra?

A lo largo de estas páginas nos propusimos aportar claves de pensamiento desde las cuales reflexionar sobre cómo socializar a niños y niñas de edad escolar en un hecho traumático del pasado reciente como la guerra de Malvinas. Recortamos para nuestro análisis un programa televisivo educativo que ha demostrado erigirse como una referencia potente para el público infantil en lo que respecta al conocimiento histórico, convencidos, de la mano de Marc Ferro, del poder que tiene sobre la formación de la identidad y la alteridad la Historia que recibimos tempranamente, por constituir el primer molde que imprime las huellas del pasado en nosotros.

Nuestro estudio destaca que el Estado nacional desde el lenguaje de los dibujos animados ha logrado restablecer un papel significativo para la palabra oficial en materia de transmisión histórica. Sin embargo, en tanto propuesta educativa oficial, constituye una oferta cultural en deuda con ciertos conceptos que hacen a la formación ciudadana y a la promoción de un pensamiento crítico a través de la enseñanza de cómo pensar históricamente a la que debe llevar la socialización en el pasado dentro de un marco educativo. Entre los elementos identificados en el análisis como obstáculo para promover estas habilidades, se destaca la persistencia de una contradicción 
histórica en la enseñanza de la historia como la que existe entre los objetivos ilustrados y los objetivos románticos bajo los que "Zamba" encara la transmisión del pasado. Esta tensión entre la función identitaria y la función cognitiva que el programa no logra resolver es, desde nuestra perspectiva, lo que contribuye a consolidar los principales problemas epistemológicos de la propuesta: los conceptos vertidos allí sobre la guerra llevan a consagrarla como una gesta patriótica (ubicando así la cuestión del conflicto bélico bajo la órbita del problema de las narraciones éticas del pasado); los sujetos nacionales que están representados en el programa, el argentino y el inglés, tienden a encarnar una versión monolítica de esas identidades y a cumplir roles paradigmáticos en el desarrollo de la historia que se cuenta (buenos y malos); la ausencia de ciertos datos como la existencia de habitantes isleños (los kelpers), así como el nombre de Galtieri junto con la presencia velada del gran apoyo que la guerra recibió de parte de la sociedad civil parecen estar al servicio de una construcción identitaria virtuosa.

Cabe agregar, como lo han señalado hasta el hartazgo los estudios de comunicación, que es en el encuentro con su público donde se completan los sentidos de un texto y esta recepción nunca es pasiva, unidireccional, ni inocente. Futuras indagaciones deberán avanzar en este sentido para aportar nuevas perspectivas sobre el programa educativo sobre el que hacen foco estas páginas. 


\section{Verónica Tobeña}

\section{NOTAS}

1. Entre las producciones cultuales oficiales destinadas a conmemorar el trigésimo aniversario de la guerra de Malvinas dirigida al público escolar se cuenta la colección audiovisual Malvinas, Soberanía y Memoria, que consta de ocho DVD producidos por los canales Encuentro y Pakapaka y que agrupa materiales de características variadas: los DVD 1 y 2 incluyen microprogramas; los DVD 3, 4, 5 y 6 son denominados "Especiales" y constan, en su mayoría, de cuatro capítulos cada uno (a excepción del DVD 4 que contiene nueve capítulos). Dentro de este grupo, el 3 y el 4 se encuadran dentro de la línea "Pensar las Malvinas", mientras que el 5 se titula "Malvinas. La historia de la Usurpación" y el 6, "Historia de un país. Argentina del siglo XX". El DVD 7 está dirigido al público infantil e incluye: la serie de dibujos animados "La asombrosa excursión de Zamba a las islas Malvinas" que aquí se analiza y un microprograma titulado "Día del veterano y de los caídos en la guerra de Malvinas". Por último, el DVD 8 contiene la película dirigida por Tristán Bauer en el año 2005, "Iluminados por el fuego", que narra los recuerdos de Esteban Leguizamón, un hombre de 40 años que en 1982, cuando tenía 18, fue llevado como soldado recluta a combatir a las islas Malvinas. Según palabras del entonces Ministro de Educación, Alberto Sileoni, el objetivo de la colección es que "este material contribuya a colocar en un lugar central la conciencia de los derechos argentinos sobre las islas Malvinas y también que sea un aporte para mantener viva la memoria de los jóvenes soldados que murieron, de sus familias y sus compañeros. (...) La causa Malvinas supone un reclamo a favor de la libertad y de la igualdad de todas las naciones, contra todo resabio colonial que exista en el mundo". Como parte de la política oficial en torno a Malvinas hay que ubicar la creación del Museo Malvinas e islas del Atlántico Sur, que funciona desde junio de 2014 en la ex sede de la Escuela Mecánica de la Armada (ESMA). En el lapso temporal circundante al 2 de abril de 2012, cuando se conmemoraba este aniversario, se vivió un clima de agitación nacionalista que volvía a señalar la denominada "cuestión Malvinas" como una política de Estado, durante la cual dentro de los sectores tanto de la dirigencia oficialista como opositora hicieron eco las reivindicaciones de soberanía sobre las islas en términos patrióticos. Lo cierto es que este clima no llegó a propagarse con fuerza entre otros sectores, sobre todo de la sociedad civil, y se fue apagando a medida que el aniversario fue quedando distante en el tiempo. Sin embargo, la exaltación del nacionalismo que propició la fecha fue lo suficientemente sobresaliente como para despertar la alarma en cierto ámbito intelectual que por entonces llamó a una reflexión responsable y madura sobre el tema, y que reclamaba examinar a fondo el modo en que se estaba reinstalando la cuestión Malvinas desde la siguiente convicción: “La opinión pública argentina está madura para una estrategia que concilie los intereses nacionales legítimos con el principio de autodeterminación sobre el que ha sido fundado el país". Y en relación a los argumentos que circulaban sosteniendo el reclamo de soberanía, se pronunciaban: "La República Argentina ha sido fundada sobre el principio de autodeterminación de los pueblos y para todos los hombres del mundo. Como país cuyos antecedentes incluyen la conquista española, nuestra propia construcción como nación es tan imposible de desligar de episodios de ocupación colonial como la de Malvinas. La Historia, por otra parte, no es reversible, y el intento de devolver las fronteras nacionales a una situación existente hace casi dos siglos -es decir: anterior a nuestra unidad nacional y cuando la Patagonia no estaba aún bajo dominio argentino- abre una caja de Pandora que no conduce a la paz" (Véase: <http://malvin-and-hobbes.tumblr.com>). 
2. Dice Escudé sobre la guerra de Malvinas: "Este curioso y traumático incidente llamó mi atención sobre el irredentismo territorial argentino, que alimentó a esa guerra y tres años antes casi provocó una guerra con Chile. Ese irredentismo está en gran medida alimentado por la creencia de que durante el siglo XIX la Argentina perdió enormes territorios: esta percepción está presente en casi todos los textos escolares de historia desde hace casi un siglo. Y esa percepción contrasta netamente con los atlas históricos que se publican en Europa y en América del Norte, todos los cuales adjudican a la Argentina, a mediados de siglo XIX, un territorio equivalente a poco más de la mitad de su territorio actual. ¿Qué significa esto?" (Escudé, 1990:XV). Escudé señala las orientaciones pedagógicas que asume la escuela frente a la enseñanza de la historia como responsables de esta tergiversación y se consagra así a su estudio para brindar con su análisis un aporte a la "comprensión de la irracionalidad en los comportamientos políticos, tanto internos como internacionales" (id., ibid.:XVII). Su convicción para hacerlo es la misma que mantiene Marc Ferro: "lo que se le enseña a la gente y es adecuadamente internalizado, tiene un impacto sobre la forma en que la gente siente, piensa y percibe, y por lo tanto incide sobre los comportamientos individuales y colectivos, sobre las políticas internas y externas de los Estados, e incluso impone límites al tipo de política que puede implementarse con éxito en una sociedad determinada" (id., ibid.: XVI-XVII).

3. Para ampliar este punto sugerimos ver Tobeña (2011), donde hemos trabajado el hiato que se abre entre la escuela y la contemporaneidad.

4. No es el propósito de este trabajo detenerse en la dimensión estética del producto en cuestión, dar cuenta de sus características en función de la gramática televisiva a la que responde o realizar un análisis del modo en que este dibujito se percibe en sintonía con otros productos del mismo género de la industria del entretenimiento -usando recursos como la intertextualidad, guiños a las competencias desarrolladas por el público infantil a partir de sus experiencias como consumidores televisivos, el uso de recursos musicales, etc.-, pero sí creemos importante señalar estas afinidades para ponderar otra cuestión que tampoco es el tema de estas páginas pero sí merece una reflexión: ¿qué ocurre con Zamba en la instancia de recepción?

5. Las efemérides y los actos patrios escolares constituyen el primer contacto de los alumnos con el pasado nacional.

6. Letra de la canción del videoclip: "Hay una colonia en el medio del mar que Inglaterra ocupa de forma ilegal. Las islas Malvinas hay que liberar, fueron argentinas, lo son y serán. Es una injusticia que hay que reparar pero con la guerra siempre sale mal. Las descubrió España en el S. XVI, Francia e Inglaterra llegaron después, gente prepotente la tierra ocupó pero con reclamos volvió el español, fue del Virreinato y la gobernación, igual Inglaterra no se resignó. Invadió Buenos Aires: 1806 y otra vez lo hizo un año después (1807). Con fuerza y coraje dijimos adiós (1816) y con la Independencia se fue el español. La Argentina libre su tierra heredó. Trece años más tarde el imperio volvió (1833). Expulsó a los criollos, banderas plantó, Vuelta de Obligado fue otra invasión (1845). No nos hace falta un emperador, no hay más colonias, la moda pasó. Es una injusticia que hay que reparar, pero con la guerra siempre sale mal".

7. En "Zamba" la soberanía argentina de las islas abreva en la argumentación de la herencia para su fundamentación: España las "descubrió" (este es el verbo que utiliza el programa para nombrar el dominio español inicial sobre este territorio) y las heredamos 


\section{Verónica Tobeña}

al independizarnos del español. "Nosotros estábamos primero" le dice Zamba al niño inglés. A ese argumento central se agrega un dato que funciona como evidencia incontestable a favor del reclamo argentino y que ancla en un criterio territorial: mientras la distancia que separa a las islas de Inglaterra es de $12.800 \mathrm{~km}$ la ubicación respecto de la Argentina es de apenas $460 \mathrm{~km}$. Para una reflexión sobre la interpelación nacionalista desde el territorialismo se sugiere ver Palermo, 2007.

8. Este diálogo se da en un clima de mucha tensión en una trinchera oscura a la que descienden tras escapar de los bombardeos ingleses (la imagen cubre la pantalla de negro y solo se ven los puntos blancos de los ojos de Sapucai y de Zamba en forma alternada, de acuerdo con quién es el que está hablando), y es el siguiente: “Z: ¡Están tirando bombas Sapucai! / S: Sí, Zamba, vamos a esperar a que termine el bombardeo para atacar de nuevo. / Z: ¿Y ahora? ¿Qué hacemos? / S: (resopla) Zamba, la verdad es que peleamos de igual a igual, pero no estamos bien equipados. Y nuestros hombres han pasado hambre y frío... están muy cansados. / Z: ¿Y entonces?" Sapucai enciende una linterna y la imagen muestra entonces a los dos personajes dentro de una especie de cueva y al soldado con un mapa de las Malvinas en la mano. El diálogo que sigue se apoya en las imágenes que se usan para ilustrar la explicación que va dando el soldado). "S: A pesar del heroísmo de los aviadores que durante semanas bombardearon los barcos ingleses, ellos lograron desembarcar en el Puerto San Carlos. Peleamos ferozmente en la Batalla de Pradera de Ganso, pero no pudimos contener el avance... Ellos son más experimentados y tienen visión nocturna. Esta noche llegarán a Puerto Argentino para conquistar la capital y adueñarse de las islas otra vez. Nuestra misión es defender Puerto Argentino desde estos montes. / Z: ¡Sapucai, terminó el bombardeo! / S: Bien. Llegó el momento de la batalla final. ¡Vamos Zamba!”.

9. El recurso utilizado para simbolizar la muerte consiste en una cruz que surge en reemplazo del soldado caído que queda coronada por su casco.

10. Esta genealogía que plantea "Zamba" no es inédita. Federico Lorenz refiere que "durante la guerra, diversas manifestaciones públicas en la Argentina inscribieron el conflicto en la épica de la historia nacional. En alusión a la Revolución de Mayo de 1810, algunos medios comenzaron a informar sobre las acciones bélicas en una sección titulada 'los nuevos héroes de Mayo', planteando una continuidad histórica en el hecho considerado inicial de la historia argentina independiente" (2014:266).

11. El primero en señalar esta falta fue el investigador Pablo Gullino (2013) en su trabajo 'A la carga mis valientes'. Representaciones mediáticas educativas a partir de un caso de la historia reciente: la guerra de Malvinas (Canal Encuentro, 2012)". Aquí avanzamos aportando algunas claves de lectura a los problemas que trae aparejada esta ausencia para la enseñanza de la historia desde nuestra perspectiva.

12. Esta afirmación no niega que la historia sea una construcción ni busca velar la naturaleza interpretativa y subjetiva de las explicaciones históricas (no existen los hechos puros), simplemente apunta a subrayar el criterio de verdad sobre el que la disciplina está obligada a regirse, que se instrumenta a partir de las regulaciones y modulaciones que a nivel metodológico pautan el oficio historiográfico.

13. Es cierto que a lo largo del dibujo animado se destilan elementos que cuestionan o ponen matices a la identificación moral con la nación, elementos que vienen a interponer razones más mundanas a las pasiones épicas que los nacionalismos agitan ("justo se les 
ocurre hacer una guerra en abril"; "el dictador nos manda pero él se queda en su casa"; "los ingleses tampoco parecen muy convencidos de estar acá"), pero estos no constituyen el eje de la reconstrucción narrativa ni constituyen los argumentos racionales centrales que organizan el texto.

14. Basta revisar el amplio arco político y social que apoyó la guerra de Malvinas y el entusiasmo con que lo hizo para sostener esta afirmación. Sugerimos la lectura del interesante trabajo de recopilación de posiciones sobre la guerra realizado por María Elena Saraví (2012) donde se puede leer, por ejemplo, parte de una solicitada publicada en el diario Clarín por un grupo de familiares de detenidos y desaparecidos de la dictadura, el cual rezaba: “En momentos en que miles de jóvenes argentinos, entre ellos nuestros hijos, sobrinos, nietos están en el sur para defender nuestra patria, no podemos dejar de pensar en nuestros detenidos y desaparecidos, que seguramente hubieran apretado filas junto a los soldados y que no pueden hacerlo por su injusta desaparición" (Clarín, 8/05/1982).

15. Lógicamente el estereotipo es un recurso muy utilizado por la industria cultural en propuestas dirigidas al público infantil porque su uso permite un mensaje eficaz, pues es rápidamente identificado y reconocido. "Zamba" demuestra no ser la excepción, pero en virtud del rol educativo para el que fue concebido exige un trabajo cuidadoso sobre aquellos aspectos que moldean las bases sobre las que se apoya más tarde la interacción social.

16. La caricaturización de esta figura no admite errores: silueta humana, parche en el ojo, sable en mano, cicatriz en la mejilla, pañuelo en la cabeza y pata de palo.

17. Esto contribuye al mérito de Chispa como piloto, ya que concluye la misión con éxito a pesar de lo rudimentario de su avión (precariedad simbolizada, por ejemplo, por un marcador de combustible que tiene como indicadores las leyendas "muy poco" y "casi nada" para informar sobre la cantidad de combustible con la que cuenta el tanque).

18. Mientras que el avión de Chispa se vale de tecnología electrónica, el del piloto inglés muestra tecnología computarizada capaz de visualizar y manejar desde una pantalla digital las acciones de guerra, y hasta cuenta con misiles inteligentes que persiguen su objetivo. Por contraste, se muestra al avión de Chispa operar mecánicamente el lanzamiento de sus misiles, que se produce directamente sobre el blanco a derribar sin ayuda de la precisión que pueden aportar dispositivos digitales.

19. El casco de Chispa se ve muy básico en comparación con el del piloto inglés, al que prácticamente este elemento de seguridad le cubre toda la cara y cuenta con un dispositivo que sale de su boca que parece una suerte de máscara de oxígeno.

20. Reprodujimos este diálogo en la nota seis. Los problemas a los que hace alusión allí Sapucai son fundamentalmente hambre, frío, cansancio y falta de equipamiento.

21. También la dinámica un tanto mecánica, casi automática, que se imprime al funcionamiento del ejército inglés en dicha batalla, al que el ataque argentino no parece hacer mella y que renueva la ofensiva tras cada repliegue del ejército sudamericano, como si se tratara de máquinas programadas para matar, contribuye a una construcción deshumanizada del enemigo anglosajón. Máxime si se tiene en cuenta que en este contexto se muestra por primera vez una figura que ya forma parte del imaginario colectivo: nuestros caídos en Malvinas. 


\section{Verónica Tobeña}

22. "Los gurkas eran mercenarios nepaleses al servicio de la corona británica, famosos por sus destrezas con las armas blancas, en especial el cuchillo curvo 'kurki'. Fueron un símbolo de la crueldad británica con los combatientes argentinos, ya que despellejaban a los heridos, todavía vivos" (Muñoz Larreta, 2013:84). Semejante violencia, de una crueldad de difícil explicitación para un producto concebido para el público infantil, se presenta edulcorada en el texto, ya que se apoya en una representación de esos enfrentamientos a imagen y semejanza de las historietas cómicas e invirtiendo el saldo que arrojaban estos enfrentamientos: Sapucai vence al gurka (el enemigo mejor entrenado para la lucha cuerpo a cuerpo), transformándose así en un héroe y a ese combate en una muestra del valor del soldado argentino.

23. Es difícil explicar con palabras qué atributos asume una risa de cariz "macabro". Apelamos en este punto a las competencias culturales del lector, a quien suponemos lo suficientemente expuesto a los medios de masas como para contar en su repertorio con más de un ejemplo que encuadra con la risa en cuestión, que es, por cierto, muy trillada.

24. Estos personajes son dos, un soldado de a pie (que es sobre el que más recae la representación del inglés en el texto) y un piloto, a los cuales se les otorga la misma risa.

25. Y habría que agregar que ese patrón sigue vigente. Mientras se escriben estas páginas la presidenta de la Argentina recuerda en un discurso que todavía existen 17 enclaves coloniales en el mundo de los cuales 10 corresponden al Reino Unido.

26. Lo cual incluye habilidades como las de "evaluar evidencias e interpretaciones, analizar el cambio a lo largo del tiempo, razonar causalmente, etc." (Carretero y Montanero, 2008:135).

27 En este sentido, hoy parece una quimera encarar la negociación diplomática a favor de la soberanía argentina sobre Malvinas sin incluir argumentos que consideren el principio de autodeterminación de los pueblos, uno de los núcleos principales de la postura británica. Para una reflexión en torno al peso que tiene este principio para pensar la cuestión Malvinas, que además se profiere desde un lugar de enunciación argentino, se sugiere ver la postura que sostiene un colectivo de intelectuales en el documento "Una visión alternativa", disponible en:<http://malvin-and-hobbes.tumblr.com/>. 


\section{REFERENCIAS BIBLIOGRÁFICAS}

CARRETERO, Mario; KRIGER, Miriam. (2010), "Enseñanza de la historia e identidad nacional a través de las efemérides escolares". in: M. Carretero y J. A. Castorina (comps.), La construcción del conocimiento histórico. Enseñanza, narración e identidades. Buenos Aires, Paidós, pp. 55-80.

CARRETERO, Mario; MONTANERO, Manuel. (2008), “Enseñanza y aprendizaje de la historia: aspectos cognitivos y culturales". Cultura y Educación, v. 20, n. 2, pp. 133-142.

CARRETERO, Mario; ROSA, Alberto; GONZÁLEZ, María Fernanda. (2006), “Introducción. Enseñar historias en tiempos de memoria”. in: M. Carretero; A. Rosa y M. F. González (comps.), Enseñanza de la historia y memoria colectiva. Buenos Aires: Paidós.

CARRETERO, Mario; VOSS, James. (2004), Aprender y pensar la historia. Buenos Aires: Amorrortu.

FERRO, Marc. (2007), Cómo se cuenta la historia los niños en el mundo entero. México, Fondo de Cultura Económica.

ESCUDÉ, Carlos. (1990), El fracaso del proyecto argentino. Educación e ideología. Buenos Aires, Instituto Torcuato Di Tella/Editorial Tesis.

ESCUDÉ, Carlos. (1997), Patología del Nacionalismo: el caso argentino. Buenos Aires, Instituto Torcuato Di Tella/Editorial Tesis.

FONTANA, Joseph. (1982), Historia: análisis del pasado y proyecto social. Barcelona, Editorial Crítica.

GUBER, Rosana. (2012), ¿Por qué Malvinas? De la causa nacional a la guerra absurda. Buenos Aires, Fondo de Cultura Económica.

GULLINO, Pablo. (2013), “'A la carga mis valientes'. Representaciones mediáticas educativas a partir de un caso de la historia reciente: la guerra de Malvinas (Canal Encuentro, 2012)". XII Jornadas Nacionales de Investigadores en Comunicación. Sarmiento, Universidad Nacional de General Sarmiento.

JELIN, Elizabeth. (2001), "Historia, memoria social y testimonio o la legitimidad de la palabra". Iberoamericana. América Latina-España-Portugal, n. 1, pp. 87-98.

LORENZ, Federico. (2014), “'Ungidos por el infortunio'. Los soldados de Malvinas en la post-dictadura: entre el relato heroico y la victimización". Cuadernos de Historia. Serie Economía y Sociedad, n. 13/14, pp. 265-287.

LORENZ, Federico. (2013), Unas islas demasiado famosas. Malvinas, Historia y Política. Buenos Aires, Capital Intelectual.

MIGNONA (2012). Zamba en las Islas Malvinas. (20m36s). Disponible en: <https://www. youtube.com/ watch?v=58wl5VMZDYo>.

MORIN, Edgar. (2000), “Identidad nacional y ciudadanía”, in P. Gómez García (coord.), Las ilusiones de la identidad. Madrid, Cátedra, pp. 17-28.

MUÑOZ LARRETA, Francisco. (2013), 'La asombrosa excursión de Zamba': un análisis de las representaciones de infancia, juego, escuela e historia. Tesina (licenciatura en Comunicación Social), Universidad de Buenos Aires, Ciudad de Buenos Aires. 


\section{Verónica Tobeña}

PALERMO, Vicente. (2007), Sal en las heridas. Las Malvinas en la cultura argentina contemporánea. Buenos Aires, Sudamericana.

RUIZ SILVA, Alexander; CARRETERO, Mario. (2010), "Ética, narración y aprendizaje de la historia nacional", in M. Carretero y J. A. Castorina (comps.), La construcción del conocimiento histórico. Enseñanza, narración e identidades. Buenos Aires, Paidós, pp. 29-54.

SARAVÍ, María Elena. (2012), "La guerra de Malvinas en la memoria de la dictadura", in S. Raggio y S. Salvatori (coords.), Efemérides en la memoria. 24 de marzo, 2 de abril, 16 de septiembre: propuestas para trabajar en el aula. Rosario, Homo Sapiens, pp. 115-139.

TOBEÑA, Verónica. (2011), “La escuela en el mundo contemporáneo. Notas sobre el cambio cultural", in G. Tiramonti (dir.), Variaciones sobre la forma escolar. Limites y posibilidades de la escuela media. Rosario, Homo Sapiens, pp. 205-237.

VARELA, Mirta. (1994), Los hombres ilustres del Billiken. Héroes en los medios y en la escuela. Buenos Aires, Colihue.

VERÓN, Eliseo. (1985), "Semiosis de lo ideológico y del poder. La Mediatización", Buenos Aires, UBA-Secretaría de Extensión Universitaria. 


\section{RESUMO \\ Da Aula de História à Televisão: A politica Educacional Argentina em torno da Questão das Malvinas 30 Anos Após a Guerra}

O artigo analisa o modo como é representada a Guerra das Malvinas num produto audiovisual oficial dirigido ao público infantil, no marco de um incipiente e progressivo interesse das autoridades nacionais por recolocar a revisão da "Questão Malvinas" na agenda política argentina. Indaga sobre as representações da guerra e dos adversários, reflete sobre os elementos apresentados para pensar a questão e propõe compreender se este material se distancia ou não da função romântica que a história tradicionalmente desempenhou como disciplina escolar, para ponderar, em função disso, seus limites e possibilidades. Nosso estudo se baseou na análise do discurso audiovisual e na comparação historiográfica. Desta indagação concluímos que, por um lado, o Estado conseguiu, a partir da linguagem dos desenhos animados, restabelecer um papel significativo para o texto oficial em matéria de transmissão histórica. Por outro, como proposta educativa oficial, constitui uma oferta cultural em dívida com certos conceitos que fazem com que a formação cidadã e a promoção do pensamento crítico, por meio do ensino de como pensar historicamente, sejam uma forma de socialização quanto ao passado num marco educativo.

Palavras-chave: Zamba; ensino de história; público infantil; guerra das Malvinas; identidade nacional

\section{ABSTRACT \\ From History Classes to Television: Argentine Educational Policies Around the Falklands Issue 30 Years After the War}

The article analyzes the way in which the Falklands War is represented in an official audiovisual product aimed at children's audiences, within the framework of an incipient and progressive interest of the national authorities to put the review of the "Falklands Issue" on the Argentine political agenda. We inquire about the representations of war and opponents, reflecting on the elements presented to think about the question and to try and understand whether this material encompasses the romantic function that history traditionally played as a school discipline, in order to consider its limits and possibilities. Our study is based on historiographic comparison and the analysis of the audiovisual discourse. From this question, we concluded that, on one hand, the State has been able, using the language of cartoons, to reestablish a significant role for the official discourse regarding historical transmission. On the other hand, as an official educational 


\section{Verónica Tobeña}

proposal, it constitutes a cultural offer indebted to certain concepts that make the formation of citizens and the promotion of critical thinking, through the teaching of how to think historically, a form of relation to the past within an educational framework.

Keywords: Zamba; history teaching; children's audiences; Falklands war; national identity.

\section{RÉSUMÉ}

De La Leçon d'Histoire à la Télévision: La Politique Éducative Argentine Autour de la Question des Malouines 30 Ans Après la Guerre

L'article analyse la manière dont la Guerre des Malouines est représentée dans un produit audiovisuel officiel destiné au public infantile, dans le cadre d'un intérêt naissant et progressif des autorités nationales de mettre la révision de la «Question des Malouines» à l'agenda politique argentin. On y enquête sur les représentations de la guerre et des opposants, on y réfléchit sur les éléments présentés pour penser la question et on y propose de comprendre si ce matériel s'écarte ou non de la fonction romantique que l'histoire a traditionnellement jouée en tant que discipline scolaire, pour en fin de compte considérer ses limites et possibilités. Cet étude était basée sur l'analyse du discours audiovisuel et sur la comparaison historiographique. De cette question, on conclut que, d'une part, l'État, à partir du langage des dessins animés, a pu rétablir un rôle significatif pour le texte officiel sur la transmission historique. Par ailleurs, en tant que proposition éducative officielle, il constitue une offre culturelle incomplète en regard à certains concepts necessaires pour une formation des citoyens et de la promotion de la pensée critique qui, travers un enseignement de comment penser historiquement, soient une manière de socialisation du passée dans un cadre éducatif.

Mots-clés: Zamba; enseignement de l'histoire; public d'enfants; guerre des Malouines; identité nationale

\section{RESUMEN}

De la Clase de Historia a la Televisión: La Política Educativa Argentina en Torno a la Cuestión Malvinas a 30 Años de la Guerra

El artículo analiza el modo en que se representa la guerra de Malvinas en un producto audiovisual oficial dirigido al público infantil, en el marco de un incipiente y progresivo interés de parte de las autoridades nacionales de 
reinstalar la revisión de la cuestión Malvinas en la agenda política argentina. Indaga sobre las representaciones de la guerra y sus contendientes, reflexiona sobre los elementos presentados para pensar la cuestión y propone discernir si este material se distancia o no de la función romántica que tradicionalmente ha desempeñado la historia como disciplina escolar, para ponderar en función de ello sus límites y sus posibilidades. Nuestro estudio se basó en el análisis del discurso audiovisual y la contrastación historiográfica. De esta indagación se desprende, por una parte, que desde el lenguaje de los dibujos animados el Estado ha logrado restablecer un papel significativo para la palabra oficial en materia de transmisión histórica. Por otra, en tanto propuesta educativa oficial constituye una oferta cultural en deuda con ciertos conceptos que hacen a la formación ciudadana y a la promoción de un pensamiento crítico a través de la enseñanza de cómo pensar históricamente a la que debe llevar la socialización en el pasado en un marco educativo.

Palabras clave: Zamba; enseñanza de historia; público infantil; guerra de Malvinas; identidad nacional 